\title{
Peripheral Neuropathy in Cockayne's Syndrome
}

\author{
A. MOOSA and V. DUBOWITZ \\ From the Department of Child Health, University of Sheffield
}

\begin{abstract}
Moosa, A., and Dubowitz, V. (1970). Archives of Disease in Childhood, 45, 674. Peripheral neuropathy in Cockayne's syndrome. A detailed study has been made of a typical case of Cockayne's syndrome. An associated peripheral neuropathy has been demonstrated by slow nerve conduction velocities and by evidence of segmental demyelination on sural nerve biopsy. Cockayne's syndrome is probably a leucodystrophy.
\end{abstract}

In 1936, Cockayne described two sibs with cachectic dwarfism, an unusual facies, scaly erythematous dermatitis associated with photosensitivity, 'peppersalt' choroido-retinitis, partial deafness, and undescended testes. When he reviewed them 10 years later (Cockayne, 1946), they were both blind, with optic atrophy and cataracts, were severely mentally retarded, and had various joint contractures. Other features he observed were a slender trunk with unduly long legs and large hands and feet. He suggested that the condition was probably a recessively inherited disorder.

Since this original description more than 20 cases of this syndrome have been described (Neill and Dingwall, 1950; McDonald, Fitch, and Lewis, 1960; Paddison et al., 1963; Windmiller, Whalley, and Fink, 1963; Spark, 1965; Wilkins, 1965; Ohno and Hirooka, 1966; and Rowlatt, 1969). In some, additional features were present, such as intracranial calcification, osteoporosis, nystagmus, tremor, diminished lachrymation and sweating, and associated renal lesions. There has, however, been no mention of a peripheral nerve involvement in any of these reports.

We present a further case of Cockayne's syndrome in which we have obtained electrophysiological and histological evidence of a demyelinating peripheral neuropathy. This should provide a useful means of confirming the diagnosis in future cases and also throw some light on the nature of the disease.

\section{Case Report}

History. This child was born at full term in April 1963, and weighed 2864 g. Though he had frequent vomiting during the early months, his weight gain was satisfactory and by 7 months had reached $7824 \mathrm{~g}$.

Received 27 February 1970
However, he subsequently failed to thrive. At 1 year of age his weight was only $7711 \mathrm{~g}$. and did not increase much subsequently.

His early developmental milestones were reached normally, but his subsequent development was delayed. He did not sit till about 14 months and never achieved the ability to walk unaided. His limbs appeared to be stiff and there was limitation of movement of various joints. From the time he was sitting he developed a gradually progressive kyphosis of the dorsal spine.

He has always been very sensitive to sunlight, and even slight exposure resulted in obvious redness and blistering of the face and associated drying and shrivelling of the skin. He has never sweated and his skin tends to be dry. He also has very little tear formation. His deciduous teeth all became carious and some had to be extracted.

At the ages of 2 and 3 years he had convulsions lasting 4 and 6 hours, respectively, which set him back in his motor activity. Between 2 and 3 years he had begun to walk with a 'baby-walker'. There has not been any obvious muscle weakness at any time. His mother has noted that the arms and legs 'look too long for his body'.

Examination. On recent examination at the age of $6 \frac{1}{2}$ years, he had a striking progeria-like appearance, and looked like a wizened old man (Fig.). The skin was dry and wrinkled, the eyes sunken, and the general appearance cachectic. The incisors of his second dentition were normal. Both his height and weight were well below the 3rd centile (Table). He was very pigeon-chested, with prominence of the sternum, already noted at birth, and associated Harrison's sulcus. There was associated kyphosis (Fig.).

Various joints showed limitation in range of movement (Fig.). There was about $30^{\circ}$ of limitation of supination in both forearms. Both hips flexed to only $90^{\circ}$, could not extend beyond $150^{\circ}$, and also had limited rotation and abduction. The knees flexed fully but could only extend to $150^{\circ}$. The fingers and toes were short and squat, and there was partial syndactyly of the 2 nd and 3 rd toes bilaterally. 


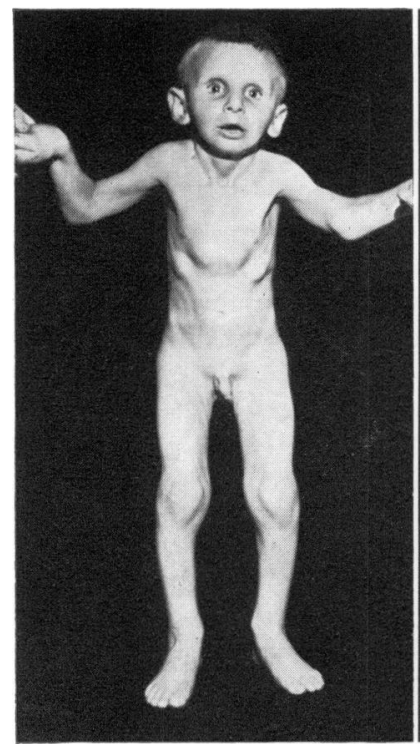

(a)

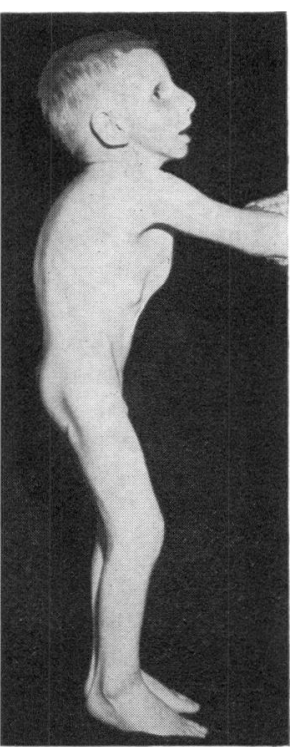

(b)
FIG.-Patient at the age $6 \frac{1}{2}$ years showing wizened appearance, kyphosis, and flexion deformities of joints.

Examination of the nervous system showed phasic nystagmus on lateral gaze to right and left. The tendon reflexes were all sluggish. The plantar response was withdrawal and difficult to assess. There was no other focal neurological abnormality.

Examination of the fundi showed normal disks and vessels, but increased retinal pigmentation, particularly in the mid-zone and peripheral region. The corneae were normal but the iris was hypoplastic. Detailed audiometric study showed no evidence of impaired hearing. There was gross intellectual impairment, his development being less than a 2-year level.

The heart sounds were normal, the heart rate 84 a minute, and the systolic blood pressure $110 \mathrm{~mm}$. $\mathrm{Hg}$. The feet were cold and blue but the peripheral pulses were palpable. Both testes were undescended.

\section{TABLE}

Body Measurements of Patient at $6 \frac{1}{2}$ Years

\begin{tabular}{l|c|c}
\hline \multicolumn{1}{c|}{ Parameter } & Patient & $\begin{array}{c}\text { Normal Child Aged } \\
\text { years (median values) }\end{array}$ \\
\hline Length (cm.) & $88 \cdot 5$ & $120 \cdot 8$ \\
Head circumference (cm.) & $42 \cdot 5$ & $51 \cdot 8$ \\
Weight (kg.) & $7 \cdot 95$ & $23 \cdot 2$ \\
Chest circumference (cm.) & $43 \cdot 0$ & $57 \cdot 0$ \\
Crown-rump length (cm.) & $44 \cdot 2$ & $66 \cdot 4$ \\
Span (cm.) & $75 \cdot 4$ & - \\
\hline
\end{tabular}

^ From Textbook of Pediatrics. Ed. by W. E. Nelson, V. C. Vaughan, and R. J. McKay, 9th edition (1969), W. B. Saunders, pages 44,50 , and 54 .
Family history. Both parents are normal and unrelated. The father is of Polish and the mother of English origin. Two sibs are also normal. There is no family history of a similar disorder.

\section{Investigations.}

Blood. The serum calcium varied from $9 \cdot 0$ to $9 \cdot 7$ $\mathrm{mg}$. $/ 100 \mathrm{ml}$., the phosphate from 4.9 to $5.6 \mathrm{mg} . / 100 \mathrm{ml}$., and the alkaline phosphatase was 21 King units. The serum sodium was $140 \mathrm{mEq} / \mathrm{l}$; the potassium $5 \cdot 7$ $\mathrm{mEq} / \mathrm{l}$.; the bicarbonate $23 \mathrm{mEq} / \mathrm{l}$., and the urea $26 \mathrm{mg}$./ $100 \mathrm{ml}$. The serum cholesterol was $260 \mathrm{mg} . / 100 \mathrm{ml}$., and the total serum lipids $870 \mathrm{mg} . / 100 \mathrm{ml}$. Chromosome analysis (leucocytes) was normal.

Urine. Screening tests for mucopolysaccharides were normal. Amino acid chromatography was normal. There was no proteinuria.

Radiology. The skull showed faint calcification, probably in the walls of the lateral ventricle and also in the posterior fossa. In the wrists and hands, the bone density was low and the bone age was advanced. When assessed at 4 years it was at approximately a 6-year level of maturation. The spine showed dorsal kyphosis. The vertebrae were relatively flattened, with a rather bullet-shaped configuration in the lower dorsal and lumbar region. The long bones were only slightly reduced in length for the patient's age, but there was abnormal flaring of the bone ends. In the pelvis, the sacrosciatic notches were somewhat acute and the $Y$ cartilages were broad. The acetabula were large with horizontal roofs. A detailed description of these radiological changes will be reported elsewhere (B. J. Whitlocke, in preparation).

Nerve conduction velocities. These were performed on 3 separate occasions, and were consistently slow. Ulnar nerve: $27 \cdot 1 ; 25.0$ and $26.9 \mathrm{~m}$./sec. (normal: approximately $55.0 \mathrm{~m} . / \mathrm{sec}$.). Posterior tibial nerve: $21 \cdot 2 ; 18 \cdot 8$ and $22.6 \mathrm{~m}$./sec. (normal: approximately $45 \cdot 0 \mathrm{~m} . / \mathrm{sec}$.).

Concentric needle electromyography of the gastrocnemius and quadriceps muscle was normal.

$E E G$. The record was of low voltage but showed no specific abnormalities.

Sural nerve biopsy. Both paraffin and frozen sections showed an over-all loss of myelinated fibres, with relative preservation of axis cylinders. Isolated teased fibres confirmed the presence of active and healing segmental demyelination. No evidence of axonal degeneration of the Wallerian type was seen.

Muscle biopsy. Routine histological and enzyme histochemical study of the right vastus medialis muscle showed a universal decrease in fibre diameter, with a range of 5 to $20 \mu$ in diameter, and a normal differentiation into the two histochemical fibre types. 


\section{Discussion}

This child shows the typical features of Cockayne's syndome, with cachectic dwarfism, a characteristic facies, photosensitivity, choroido-retinitis, intracranial calcification, mental retardation, and contractures of joints. In addition, we have shown the presence of a peripheral neuropathy.

Peripheral neuropathy is not always easy to diagnose in young children, especially when it is associated with severe mental retardation. Accurate assessment of sensory function in the limbs may be virtually impossible. The diagnosis is often suspected on the basis of muscle weakness and wasting, or diminished or absent tendon reflexes. In our case, however, there was no obvious wasting or weakness of any muscle group, sensation was impossible to assess, and the only findings suggestive of a peripheral neuropathy were the sluggish tendon reflexes and possibly the cold, blue extremities. Because of the joint deformities and apparent contractures, a full neuromuscular assessment was done. The nerve conduction studies showed unequivocal evidence of peripheral nerve involvement with consistently slow rate of conduction in both the ulnar and posterior tibial nerves.

In none of the earlier cases of Cockayne's syndrome were nerve conduction studies reported. It is thus possible that associated peripheral neuropathy may have been missed. Some of the features described in a number of the reports suggest it may have been present. Thus the scaly erythematous dermatitis together with the cold blue hands and feet in Cockayne's cases were thought to be trophic in nature. One of Neill and Dingwall's (1950) cases had frequent limb pains and a tendency to fall. Spark (1965) reported a generalized decrease in tone and diminished deep tendon reflexes in his two cases. One of the cases of Paddison et al. (1963) had 'generalized muscular atrophy with diminished reflexes'. The second case described by Ohno and Hirooka (1966) had a right facial palsy.

Slow nerve conduction velocity usually implies segmental demyelination due to Schwann cell damage. This was confirmed by the sural nerve biopsy, where both in fixed and teased preparations there was unequivocal evidence of segmental demyelination. There are several conditions associated with segmental demyelination of peripheral nerve (Cragg and Thomas, 1964; Thomas and Lascelles, 1965; Waksman, Adams, and Mansmann, 1957; Chopra and Hurwitz, 1967). Of particular interest in the present context of a child with a progressive central nervous system disorder and associated peripheral neuropathy, are some of the leucodystrophies. These include metachromatic leucodystrophy and Krabbe's globoid cell leucodystrophy, in both of which slow conduction velocity associated with segmental demyelination have been described (Fullerton, 1964; Dunn et al., 1969).

There are several points of similarity between Cockayne's syndrome and the leucodystrophies. Clinically both present, after an initial period of apparent normality, as a progressive disorder of the central nervous system, eventually leading to severe mental retardation, blindness, deafness, and death by inanition and infection. Cerebellar and extrapyramidal signs such as ataxia, nystagmus, tremors, and muscular rigidity are common to both. Deep tendon reflexes may be diminished or absent and yet the plantar response may be extensor, indicating both a peripheral nerve and pyramidal tract involvement. Renal lesions have been described in both Cockayne's syndrome (Ohno and Hirooka, 1966) and metachromatic leucodystrophy (Hagberg, Sourander, and Svennerholm, 1962).

There is a great variation in the natural history of the various types of leucodystrophies, particularly with regard to the time of onset and rate of progression. There is, however, a striking similarity in the early history of Cockayne's syndrome and metachromatic leucodystrophy (MLD). In MLD the infants develop normally in the first year of life, and symptoms and signs usually manifest themselves in the second or third year. Similarly, in Cockayne's syndrome, symptoms and signs usually appear in the second year of life, though the photosensitive dermatitis may appear earlier. In Cockayne's syndrome, however, the progression of the disease is generally much slower than in MLD. In contrast, in Krabbe's leucodystrophy, the disease usually manifests itself in the first year and often progresses fairly rapidly to a fatal outcome.

Neuropathological evidence also suggests that Cockayne's syndrome may be one of the leucodystrophies. In one of McDonald's cases (quoted by Gellis, 1961-62) necropsy showed many patches of demyelination in the subcortical white matter, brain-stem, and cord, associated with widespread loss of neurones, and areas of necrosis and calcification in cerebral white matter. Moossy (1967) and Rowlatt (1969) described similar changes in the brains of their cases of Cockayne's syndrome. Norman and Tingey (1966) described, under the title of 'syndrome of microencephaly, strio-cerebellar calcification and leucodystrophy', a patient whose brain also showed a patchy type of demyelination associated with small amounts of sudanophil lipids and well-preserved axis cylinders. Calcification 
was also present in the putamina and cerebellum. Chemically the myelin showed a marked loss of myelin lipids and increase of cholesterol esters. Clinically this patient appears to have had Cockayne's syndrome and histologically there was evidence of leucodystrophy. Similar changes were found by Norman and Tingey (1966) in the brains of the two cases described by Neill and Dingwall (1950).

On the basis of these neuropathological findings as well as biochemical studies, Norman and Tingey (1966) suggested that this condition was a type of genetically determined leucodystrophy (sudanophil type). Moossy (1967) agreed with this hypothesis but suggested, in view of loss of neurones found in his case, that degenerative metabolic neuronal changes were present in addition to the leucodystrophic changes. Similar loss of neurones was seen in the brain of McDonald's case at necropsy (Gellis, 1961-62).

Cases of dwarfism, microcephaly, and cerebral calcification with neuropathological features of patchy demyelination have also been described under the name of Pelizaeus-Merzbacher disease. This disease is one of the demyelinating disorders and has been classified as a form of sudanophil leucodystrophy (Norman et al., 1966). Peripheral nerve involvement has not been described in this condition.

It appears that the same syndrome of dwarfism, microcephaly, cerebral calcification, and patchy demyelination has been described under various names. There seems little doubt that clinically and neuropathologically Cockayne's syndrome is one of the progressive demyelinating disorders of the nervous system. Though in some cases neuronal loss is evident as well, the predominant neuropathological feature is one of patchy demyelination. It is therefore reasonable to consider it a form of leucodystrophy, as Norman and Tingey (1966) suggested. The segmental demyelination observed in the peripheral nerve of our case lends further support to this hypothesis. The basic defect causing this syndrome still remains to be determined, but it is almost certainly an inborn error of lipid metabolism, probably inherited as an autosomal recessive.

We thank Dr. T. Wright for referring the patient, Dr. A. D. Dayan for his report on the sural nerve biopsy, $\mathrm{Mr}$. B. Garston for the ophthalmological assessment, Dr. T. Powell for the radiological report, Miss C.
Heinzman and Mrs. B. Lunn for technical assistance, and Mr. A. Tunstill for the photographs. The neuromuscular research programme is supported by grants from The Muscular Dystrophy Group of Great Britain and The Medical Research Council.

\section{REFERENCES}

Chopra, J. S., and Hurwitz, L. J. (1967). Internodal length of sural nerve fibres in chronic occlusive vascular disease. Fournal of Neurology, Neurosurgery and Psychiatry, 30, 207.

Cockayne, E. A. (1936). Dwarfism with retinal atrophy and deafness. Archives of Disease in Childhood, 11, 1.

- (1946). Case reports: dwarfism with retinal atrophy and deafness. Archives of Disease in Childhood, 21, 52.

Cragg, B. G., and Thomas, P. K. (1964). Changes in nerve conduction in experimental allergic neuritis. Fournal of Neurology, Neurosurgery and Psychiatry, 27, 106.

Dunn, H. G., Lake, B. D., Dolman, C. L., and Wilson, J. (1969). The neuropathy of Krabbe's infantile cerebral sclerosis (globoid cell leucodystrophy). Brain, 92, 329 .

Fullerton, P. M. (1964). Peripheral nerve conduction in metachromatic leucodystrophy (sulphatide lipidosis). fournal of Neurology, Neurosurgery and Psychiatry, 27, 100.

Gellis, S. S. (1961-62). Editor, The Year Book of Pediatrics, p. 468. Year Book Medical Publications, Chicago.

Hagberg, B., Sourander, P., and Svennerholm, L. (1962). Sulphatide lipidosis in childhood. American fournal of Diseases of Children, 104, 644.

McDonald, W. B., Fitch, K. D., and Lewis, I. C. (1960). Cockayne's syndrome. A heredofamilial disorder of growth and development. Pediatrics, 25, 997.

Moossy, J. (1967). The neuropathology of Cockayne' syndrome. fournal of Neuropathology and Experimental Neurology, 26, 654.

Neill, C. A., and Dingwall, M. M. (1950). A syndrome resembling progeria : a review of two cases. Archives of Disease in Childhood, 25, 213.

Norman, R. M., and Tingey, A. H. (1966). Syndrome of microencephaly, striocerebellar calcifications and leucodystrophy. fournal of Neurology, Neurosurgery and Psychiatry, 29, 157.

- Tingey, A. H., Harvey, P. W., and Gregory, A. M. (1966). Pelizaeus-Merzbacher disease: a form of sudanophil leucodystrophy. Fournal of Neurology, Neurosurgery and Psychiatry, 29, 521 .

Ohno, T., and Hirooka, M. (1966). Renal lesions in Cockayne's syndrome. Tohoku fournal of Experimental Medicine, 89, 151.

Paddison, R. M., Moossy, J., Derbes, V. J., and Kloepfer, W. (1963). Cockayne's syndrome: a report of five new cases with biochemical chromosomal, dermatologic, genetic and neuropathologic observations. Dermatologia Tropica, 2, 195.

Rowlatt, U. (1969). Cockayne's syndrome. Report of a case with necropsy findings. Acta Neuropathologica, 14, 52.

Spark, H. (1965). Cachectic dwarfism resembling the CockayneNeill type. Fournal of Pediatrics, 66, 41 .

Thomas, P. K., and Lascelles, R. G. (1965). Schwann-cell abnormalities in diabetic neuropathy. Lancet, 1, 1355.

Waksman, B. H., Adams, R. D., and Mansmann, H. C., Jr. (1957). Experimental study of diphtheritic polyneuritis in the rabbit and guinea pig. I. Immunologic and histopathologic observations. Fournal of Experimental Medicine, 105, 591.

Wilkins, L. (1965). The Diagnosis and Treatment of Endocrine Disorders in Childhood and Adolescence. 3rd ed., p. 163. C. C. Thomas, Springfield, Illinois.

Windmiller, J., Whalley, P. J., and Fink, C. W. (1963). Cockayne's syndrome with chromosomal analysis. American fournal of Diseases of Childhood, 105, 204.

Correspondence to Dr. V. Dubowitz, The Children's Hospital, Western Bank, Sheffield, S10 2TH. 